\title{
CONECTADAS: EXPERIÊNCIA DE SUBALTERNIDADE E AJUDA- MÚTUA FEMININA ONLINE ENTRE MULHERES DE CLASSES POPULARES ${ }^{1}$
}

\author{
LARA FACIOLI ${ }^{2}$ \\ RICHARD MiSKOLCI ${ }^{3}$
}

Resumo

O objetivo deste texto é analisar a ressignificação da experiência de subalternidade tal qual experenciada por mulheres das classes populares que se relacionam em rede por meio das mídias digitais. O uso dessas mídias aponta para novas formas de subjetivação e interseccionam, principalmente, diferenças de classe e gênero. Para isso realizamos pesquisa etnográfica mediada e multisituada tanto em plataformas e aplicativos constituidores das redes sociais como o Facebook, o site Bolsa de Mulher, grupos criados via whatsapp; como em ambientes offline que compõem o cotidiano dos sujeitos da pesquisa, no caso, a Baixada Fluminense e a região pobre da Zona Oeste do Rio de Janeiro.

Palavras-chave: Mídias digitais. Classe social. Gênero. Horizontes de aspiração.

\footnotetext{
1 Este artigo sintetiza resultados preliminares de uma pesquisa de doutorado em andamento, com financiamento CAPES, com os já consolidados em mestrado, conduzido com Bolsa FAPESP. Ele também incorporou reflexões teórico-metodológicas conduzidas pelo orientador do trabalho, Richard Miskolci, em pesquisa desenvolvida com Bolsa Produtividade em Pesquisa do CNPq.

2 Mestra e doutoranda do Programa de Pós-Graduação em Sociologia da UFSCar, membro do Quereres - Núcleo de Pesquisa em Diferenças, Gênero e Sexualidade. Email: larafacioli@ yahoo.com.br

3 Departamento e Programa de Pós-Graduação em Sociologia da UFSCar/Pesquisador do CNPq/Coordenador do Quereres -Núcleo de Pesquisa em Diferenças, Gênero e sexualidade. Email: ufscar7@gmail.com.
} 


\title{
CONNECTED WOMEN: SUBALTERN EXPERIENCE AND ONLINE FEMININE SELF-HELP IN POPULAR CLASSES
}

\begin{abstract}
The objective os this paper is to analyze the resignification of subaltern experience as lived by women of popular classes that relate to each other through digital media. We observe how the use of these media points out toward new forms of subjectivation and that intersec, especially, with differences of class and gender. Therefore we conducted multilocated and mediated ethnographic research in online platforms like Facebook, Bolsa de Mulher, Whatsapp groups as in offline environments that mold the everyday lives of our subjects, mainly Baixada Fluminense and the poor West region of Rio de Janeiro.
\end{abstract}

Key-Words: Digital media. Social class. Gender. Aspirational horizons.

\section{INTRODUÇÃo}

Comecei a usar computador acho que em 2000, para o trabalho. Tinha acesso ao ICQ. Passados os anos, nas empresas onde trabalhei sempre tive acesso, alguns mais limitados outros menos. Mas a partir de 2005, a cada surgimento de uma nova ferramenta de internet (MSN, Gmail, Orkut, Facebook) eu aderia, mas a utilização era só em computadores de trabalho, lan houses e terceiros. Em 2009 entrei aqui no escritório onde trabalho e tenho acesso livre a qualquer site ou rede social. Adquiri o meu computador em 2010 com objetivo de facilitar minha vida escolar e ter mais liberdade para navegar. Como sempre gostei de redes sociais, descobri o Bolsa em 2011. Eu entrei no Bolsa pelo link que abre no MSN e que dá acesso pra lá. Vi que tinha opções de fórum nos sites quando se cadastra e como sou fã de internet, achei uma oportunidade de ser quem eu sou integralmente, sem mostrar o rosto. Não gosto de todas as redes, mas sou fã em me conectar com as pessoas, por isso vi uma oportunidade lá, de expressar minhas opiniões, aconselhar. 


\section{L}

eila mora em Belo Horizonte, tem 29 anos e trabalha como assistente administrativa em um escritório de advocacia empresarial, mas começou a trabalhar muito cedo para ajudar em casa. Na época em que cedeu o depoimento acima cursava Recursos Humanos na PUC, com bolsa parcial, mas teve que trancar o curso por problemas financeiros. Leila é evangélica, afastou-se da igreja por um tempo, mas voltou a se engajar após terminar um relacionamento. Mora com a mãe e não tem muito contato com o pai, que deixou a família por não estar preparado para ter filhos.

Leila, assim como a maioria das outras mulheres com quem tivemos contato durante a etnografia desenvolvida entre 2011 e 2014, tem uma vida marcada pelas dificuldades econômicas, sociabilidade restrita e desejos de encontrar um companheiro, casar-se e constituir família. Tratam-se de aspirações que, à primeira vista, parecem apontar para uma dinâmica unicamente conservadora, mas, por meio do acompanhamento de suas histórias de vida durante quatro anos, é possível perceber algo repleto de nuances.

As colaboradoras da investigação não tiveram a família com a qual sonham. Seus pais não cursaram universidade e tampouco puderam aspirar à uma vida melhor em termos econômicos. Elas mesmas conheceram essa realidade até vivenciarem uma expansão de seus horizontes de aspiração e aquilo que alguns trabalhos acadêmicos, relatórios governamentais e coberturas midiáticas têm definido como a emergência de uma "nova classe média" ou a "ascensão da classe C".

Neste trabalho, observamos que o acesso às mídias digitais é fundamental para a sociabilidade entre mulheres que têm vivenciado, por um lado, um processo de melhoria das condições de vida e, por outro, mudanças nos referenciais de relação afetiva e amorosa. Por meio das histórias de vida de nossas interlocutoras, nosso objetivo é mostrar como é ressignificada a experiência de subalternidade desses 
sujeitos por meio da dinâmica de rede e do contato proporcionado e intensificado pela tecnologia.

Utilizamos a categoria "subalterno", como tratado pelos saberes insurgentes ${ }^{4}$, cuja influência principal acontece por meio do clássico texto de Gayatri Spivak - Pode o Subalterno Falar? - para adjetivar e caracterizar as experiências apresentadas aqui, sem deixar de abordar o que elas têm de específico em um contexto como o brasileiro.

O debate sobre subalternidade aparece na introdução à obra da teórica indiana como sendo diferente da ideia de marginalização e marcando, ao contrário, as "camadas mais baixas constituídas por modos específicos de exclusão dos mercados, da representação política legal e da possibilidade de se tornarem membros plenos do Estado dominante" (SPIVAK, 2010, p. 12).

A atenção de Spivak está voltada para as mulheres indianas e as mulheres são também sujeitos fundamentais neste trabalho. Segundo ela, dentre os sujeitos subalternos possíveis são as mulheres que mais ficam na obscuridade, de tal forma que "questionar a mudez da mulher subalterna não é invocar sua identidade sexual definida como essencial e privilegiar experiências associadas a essa identidade." (SPIVAK, 2010, p. 88), mas é tentar explicitar os diversos discursos que atravessam este sujeito.

O termo subalternidade aqui é mobilizado no sentido de apontar para experiências, não somente de pobreza e de falta de acesso a bens materiais, mas que são compostas por diferenças de gênero que posicionam os sujeitos em uma trama de relações geradora

\footnotetext{
4 Os chamados saberes insurgentes, que incluem, principalmente, os estudos pós-coloniais e a teoria queer, surgem em oposição às correntes hegemônicas do marxismo que deixaram de corresponder aos agentes de sua época, aos quais se somaram os imigrantes, negros, mulheres e homossexuais. Como aponta Richard Miskolci, "as demandas feministas, de imigrantes de ex-colônias, de movimentos negros e homossexuais impulsionaram empreendimentos científicos que colocaram em xeque formas canônicas de compreender as desigualdades sociais" (MISKOLCI, 2009, p. 159).
} 
de instabilidades e incertezas a respeito do futuro, dos projetos de aspiraçãoe das questões afetivas. Trata-se de uma inserção em contextos atravessados por sensações constantes de insegurança econômica, mas também de gênero, na medida em que existe uma forte demanda às mulheres pela composição de relações afetivas. E, por fim, trata-se de compreender que estas experiências de subalternidade se referem a uma origem familiar específica, inserida em contextos pobres que mantém padrões de gênero.

$\mathrm{O}$ acesso recente à internet representa uma possibilidade de ressignificação da experiência dessas mulheres e, a partir do uso da rede e de uma etnografia realizada por meio da observação da dinâmica online entre mulheres, nos propomos a realizar o intento apontado por Spivak. Ou seja, tentaremos compreender os processos sociais que fazem com que estes sujeitos estejam, por muito tempo, alocados em espaços de invisibilidade, sendo a rede social online uma possibilidade de agência, de troca, de negociação, e, por vezes, de acesso a conhecimentos que permitem problematizar as próprias experiências e constituir ações que negociam com discursos hegemônicos.

A entrada na rede, das mulheres que colaboraram nessa pesquisa, deu-se em meio a um processo tão profundo quanto incerto de transformações sociais e econômicas, bem como de expansão do acesso às mídias digitais nos últimos anos. Estes processos parecem ter alargado seus horizontes em meio a tensões cotidianas que envolvem o fato de ser uma mulher vinda "de baixo". Em outras palavras, sua aparente ascensão recente não tem se dado sem contradições, as quais tendem a ser ignoradas no tom positivo que permeia os dados socioeconômicos, os quais ignoram especificidades de gênero, estas últimas abordadas pelos próprios sujeitos nas redes sociais das quais fazem parte.

O termo que vigora em discursos, principalmente do governo - “Nova Classe Média" - é fruto de pesquisa realizada há mais de uma 
década pelo Centro de Políticas Públicas da Fundação Getúlio Vargas. A centralidade do argumento de Marcelo Neri, criador do termo, está posta no aspecto da renda e o tom celebratório atribuído a este processo de ascensão econômica parece não atentar para nenhuma das tensões tratadas neste texto:

\begin{abstract}
Nova Classe-Média foi o apelido que demos a Classe C há anos. Chamar a pessoa de Classe $\mathrm{C}$ soava depreciativo pior do que Classe A ou B, por exemplo. Nova Classe Média difere em espírito da expressão Nouveau riche, que acima de tudo discrimina a origem das pessoas. Nova Classe Média dá o sentido positivo e prospectivo daquele que realizou - e continua a realizar - e sonho de subir na vida (NERI, 2011, p. 19).
\end{abstract}

Somam-se a esta vertente acadêmica que celebra a suposta ascensão social das antigas classes populares discursos midiáticos não menos poderosos e que se aproximam mais das pessoas dessa pesquisa. Pesquisa realizada pela Editora Abril, já entre os meses de março e julho de 2011, que levou o nome de As poderosas da Nova Classe Média, buscou traçar o que seria o perfil e os hábitos de consumo de mulheres com aspectos similares aos de nossas colaboradoras de pesquisa. $\mathrm{O}$ levantamento de dados aconteceu com 30.600 pessoas em 26 estados, envolveu observações etnográficas, grupos de discussões e entrevistas com especialistas, dentre os quais figuram três acadêmicos e um autor de novela 5 . O resultado evidencia que se essa "Nova Classe Média" tem um gênero preponderante, ele é feminino, pois são as mulheres que tomariam a dianteira do consumo.

Este enunciado da "mulher poderosa" se expande para fora das questões que envolvem meramente o acesso a novos bens e mercadorias - que segundo a pesquisa seriam viagens de avião, internet banda larga, smartphones. É reforçado com frequência -

http://www.poderosasdanovaclassemedia.com.br/index.html. 
principalmente em livros e sites voltados para as mulheres desse estrato social - a necessidade de assumirem as rédeas tanto da esfera profissional quanto da família e das relações afetivas ${ }^{6}$. Tais discursos alocam-nas em posições contraditórias ou, ao menos, tensionadas: por um lado é dada uma ênfase no controle da vida profissional e no acesso ao consumo possibilitado pelo suposto processo de ascensão social; por outro lado, também há enunciados que as interpelam como responsáveis pela esfera afetiva, pela conquista do par amoroso e pela felicidade do casal.

$\mathrm{O}$ acesso a produtos diversos, somado ao uso das mídias digitais, principalmente para trocas de experiências com outras mulheres, tem transformado de forma considerável o horizonte aspiracional delas e as posicionado frente a um maior critério de seletividade de parceiros e de avaliação sobre o relacionamento que compensa ser mantido ou não; e, mais do que isso, as permite discutir de forma intensa problemas diversos tanto na vida em família, quanto na esfera profissional.

Neste artigo, optamos por analisar a forma como uma parte considerável das mulheres que acessam esses novos produtos na esfera do consumo, as mídias digitais e, especificamente uma rede social chamada Bolsa de Mulher, apontam tanto para as mudanças, quanto para a manutenção de velhos dilemas envolvendo a condição de mulheres nas classes populares.

Em outras palavras, apesar das possíveis transformações no horizonte aspiracional e no acesso a bens, a sociabilidade em rede mostra uma experiência feminina subalterna que mescla tanto estar

\footnotetext{
6 Um exemplo dos discursos da "mulher poderosa", aquela bem sucedida profissionalmente, mas que também não deixa de resolver-se na esfera afetiva e amorosa, é comum entre os livros de autoajuda direcionados a este público. Dentre os títulos mais famosos figuram: $O$ Que Toda Mulher Inteligente Deve Saber; Mulheres Ousadas Chegam Mais Longe; Comer, Rezar, Amar; Por que os homens amam as mulheres poderosas, etc. Já entre os sites estão, principalmente o Bolsa de Mulher e o site lançado pela ex-jornalista Ana Paula Padrão, chamado Tempo de Mulher.
} 
em uma situação ainda pouco garantidora de uma real autonomia financeira e ter uma história familiar ligada a estratos de baixa renda, quanto ser demandada para conseguir ou manter uma relação amorosa que possa proporcionar segurança econômica e emocional, bem como culminar no casamento.

Nosso campo de pesquisa une duas frentes complementares, uma online e outra offline, dentro de um mesmo procedimento que definimos como etnografia com o uso de mídias digitais. Entre 2011 e 2013, a etnografia foi iniciada com usuárias de um site chamado Bolsa de Mulher assim como em um grupo criado por elas no Facebook. À interação pelo site se seguiram contatos mais individualizados por meio de e-mails, uso de plataformas de videoconferência, mensagens de texto por celular e ligações telefônicas. Foram entrevistadas vinte mulheres, das quais algumas se tornaram colaboradoras mais próximas. Somaram-se aos contatos mediados três incursões etnográficas presenciais na Baixada Fluminense e na Zona Oeste do Rio de Janeiro, locais de moradia de uma parte das colaboradoras da investigação.

Em suma, a pesquisa envolve procedimentos qualitativos como entrevistas em profundidade e observação participante que associa os próprios meios digitais às metodologias de pesquisa existentes de forma a explorar melhor o espaço relacional em que se inserem e no qual essas mulheres dispendem boa parte de seu cotidiano. Referimonos a "espaço relacional" no sentido utilizado por Scott McQuire (2008, p. 9), ou seja, como a moldura que define a experiência social na sociedade contemporânea marcada pelo uso de mídias digitais:

Espaço relacional nomeia a configuração espacial ambivalente que emerge quando abandonamos a natureza do espaço social como dado em favor da constituição ativa de conexões espaciais heterogêneas ligando o íntimo ao global. O espaço relacional é a experiência da subjetividade 
refeita na demanda expandida aos indivíduos que façam escolhas de vida na aparente falta de coletividades tradicionais.

A definição de McQuire é esclarecedora sobre a experiência das colaboradoras dessa investigação, as quais se conheceram e criaram uma rede relacional por meio de uma plataforma comercial, o portal Bolsa de Mulher. Trata-se de um site criado pelo grupo Bolsa de Mulher AS, no ano 2000, e com atual sede em São Paulo, mas que teve sede inicial na cidade do Rio de Janeiro. Segundo os relatos de nossas colaboradoras e fontes do próprio site, ele passou a se popularizar no Brasil entre 2006 e 2009. O Bolsa funciona como uma rede social feminina em que as mulheres elaboram fóruns de debate, principalmente sobre a esfera da intimidade, da família e dos relacionamentos amorosos. No Bolsa, foram selecionados os perfis mais atuantes com os quais estabelecemos conversas de acompanhamento ao longo de dois anos sobre as vidas das interlocutoras.

As usuárias do site são, em sua maioria, jovens mulheres que trabalham na área administrativa, em ocupações como secretariado, escritórios de advocacia e contabilidade e também no comércio. Desse modo, apresentam em comum a participação profissional no Setor Terciário, esfera que mais cresceu na última década e mais abarca os empregados das classes populares, como apontam pesquisas recentes (POCHMANN, 2012; SCALON; SALATA, 2012). Em torno de dez colaboradoras da pesquisa foram ou são casadas, sete têm filhos e quatro deixaram o trabalho, mesmo que temporariamente, dividindo a rotina dos afazeres do lar com a navegação pela internet; as demais são solteiras e não exercem a maternidade.

Ainda que a internet comercial tenha se iniciado, no Brasil, entre 1996 e 1997, a partir das entrevistas, constatamos que nossas interlocutoras tiveram acesso a ela primeiro pelo trabalho, em lan- 
houses ou apenas com o barateamento dos equipamentos e serviços de acesso. Essas usuárias que adentraram a rede são novatas no mundo online, pois chegaram após aqueles sujeitos de classe média alta que estão na rede, no Brasil, desde seu surgimento.

Dentre as mais jovens, é comum a conclusão de curso universitário em instituições privadas de ensino, com financiamento para pagar depois da conclusão, como o Fundo de Financiamento Estudantil (FIES), ou através do Programa Universidade para Todos (Prouni), ambos os programas criados na década de dois mil como parte do intuito governamental de democratização do ensino superior. Parte considerável das mulheres é parda ou preta. Na composição dos tópicos de seus perfis online é comum a menção a obras e autores de autoajuda ou escritos religiosos, principalmente de caráter evangélico ou espírita.

A distribuição geográfica das usuárias do Bolsa se mostrou um dado interessante para compreender como o acesso à internet se dá para essas pessoas. Em uma pesquisa etnográfica conduzida com meios digitais, tivemos que lidar com uma forma de delimitação do campo em que a geografia tradicional passou a se associar ao espaço relacional criado em rede e vivenciado pelas mídias. Esta forma de pensar o espaço não segue a geografia em termos de definição das fronteiras de um campo, mas pode ser delimitada pelas características que compõem a rede em termos de gênero, renda, origem étnicoracial, religião, entre outras. No campo em pauta, trata-se de uma rede que mesmo se expandindo na forma de uma mancha geográfica extensa - evidente no perfil de acesso localizado nas regiões periféricas e de baixa renda do país - guarda elementos unificadores, os quais, inclusive, definiram sua expansão e viabilizaram a pesquisa.

A rede social estudada ganhou relativa autonomia em relação ao site em que se iniciou, pois parte das usuárias criou um grupo no Facebook assim como expandiu e manteve a rede inicial. Posteriormente, por outros 
meios como plataforma de videoconferência, e-mails, celulares, sendo estes últimos, mais usados recentemente, principalmente no tocante à criação de grupos no aplicativo de conversas chamado whatsapp ${ }^{7}$. Daí ser possível afirmar que este campo foi delimitado por essa rede ativamente criada por um conjunto de usuárias que selecionou as componentes a partir de seus critérios próprios. Esse tipo de dinâmica criada por meios digitais é um fenômeno recente que impõe desafios metodológicos, assim como demanda novas ferramentas teóricas para sua compreensão e análise, além de exigir uma atualização constante dos meios de pesquisa que migram daqueles restritos ao computador, para as redes móveis de acesso constante ${ }^{8}$.

Tanto no grupo formado pelas usuárias na rede social Facebook, quanto naquele presente no Whatsapp, ambos mais restritos do que o Bolsa de Mulher, é notória a centralidade de temas envolvendo suas vidas pessoais e família. Foi nesse contexto que conseguimos estabelecer maior diálogo com elas, bem como acessar aspectos de seus cotidianos pessoais, de trabalho e lazer. Logo percebemos que, a despeito das diferentes localizações geográficas das quais acessavam a rede, as usuárias partilhavam referências culturais comuns. $\mathrm{O}$ espaço relacional criado online, portanto, constituía um contexto cultural mais homogêneo do que a origem regional de suas componentes nos faria pensar. Assim, a rede em si mesma nos fazia reavaliar o que compreendemos como a delimitação de um campo investigativo na era das mídias digitais, em especial em um país em que o acesso a elas é tão desigual.

De acordo com a Pesquisa Nacional por Amostra de Domicílio (PNAD), entre 2005 e 2011, o aumento no número de pessoas com acesso à internet no Brasil foi de 143,8\% e já atingia cerca de 78 milhões

\footnotetext{
7 O Whatsapp é um aplicativo para smartphones por meio do qual os sujeitos podem estabelecer conversas síncronas e assíncronas com as pessoas da agenda telefônica do aparelho. O app permite troca de mensagens de texto, voz, compartilhamento de fotos e vídeos e criação de grupos fechados de discussão.

8 Sobre metodologia para pesquisas envolvendo mídias digitais consulte Miskolci (2012).
} 
de pessoas com 10 anos ou mais de idade. Em termos regionais, a pesquisa realizada em regiões metropolitanas do país, mostra que nas Regiões Sudeste, Sul e Centro-Oeste mais da metade da população já tinha acesso à rede, mas que o maior aumento no número de usuários em termos absolutos tem sido nas regiões Norte e Nordeste. Ainda que homens fossem maioria no acesso, há um aumento recente no número de usuárias mulheres, as quais também têm despontado como maioria na posse de celulares.

Este artigo explora, a partir das experiências e vivências de nossas colaboradoras, como as transformações econômicas recentes têm se articulado ao acesso à rede entre mulheres das classes populares. Nesse sentido, a seguir inserimo-nos no debate em curso sobre a suposta ascensão do que alguns chamam de Classe C, Nova Classe Média ou Nova Classe Trabalhadora, propondo uma compreensão diversa do fenômeno, a qual envolve uma perspectiva de gênero e outros marcadores sociais das diferenças. Apresentamos uma compreensão sociológica de classe-social que reconhece a "experiência" (THOMPSON, 1987; SCOTT, 1998) como um de seus componentes delimitadores, no caso, uma experiência de subalternidade social generificada e não superada por indicadores de avanço econômico recentes.

Por fim, na terceira parte, voltaremos à reflexão mais focada no campo de pesquisa buscando compreender como nossas colaboradoras têm feito uso das mídias digitais e como esta experiência de conexão traz uma nova forma de lidar com as tensões entre, por um lado, a origem subalterna, as poucas ferramentas disponíveis para criar caminhos de ascensão e, por outro, a ampliação dos horizontes aspiracionais compartilhados pela rede de sociabilidade via internet. 
A despeito de consensos sobre o aumento da renda e do consumo dos mais pobres, o aumento do emprego e da formalização do trabalho, há divergências importantes sobre se isto estaria criando uma nova classe, a Nova Classe Média ou Classe C, estrato que englobaria, supostamente, o público desta pesquisa.

Há perspectivas analíticas diversas, desde aquelas que celebram o que definem como "nova classe média" (NERI, 2011), passando por aquelas que sublinham a conservação do trabalho na base da pirâmide social e falam de uma "nova classe trabalhadora" (CHAUÍ, 2013; POCHMAN, 2012; SOUZA, 2012) até as que atentam também para a manutenção de eixos de desigualdade que se somam e reforçam a disparidade econômica (SCALON; SALATA, 2012).

O criador do termo "Nova Classe Média", Neri, trabalha a partir de uma análise por meio da renda, dividindo a população em quatro faixas: $\mathrm{AB}, \mathrm{C}, \mathrm{D}$ e E. Já no primeiro capítulo de sua obra " $A$ Nova Classe Média Brasileira", lança uma provocação aos sociólogos, exigentes no tocante à definição dos conceitos, justificando seu recorte de pesquisa: "Os sociólogos podem relaxar, pois não estamos falando de classe social (operariado, burguesia, capitalistas, etc.), mas de estratos econômicos" (NERI, 2011, p. 17).

Em contraposição às teorias que abordam a questão das classes por divisão de estratos com base na avaliação da renda, tem-se um esforço, de outras vertentes de pensamento, que apontam como acontecimento fundamental uma alteração na relação entre rendas do trabalho e da propriedade durante a primeira década dos anos 2000. Tal movimento encontra influência direta do impacto na estrutura produtiva, provocado pelo retorno do crescimento econômico, após quase duas décadas de estagnação: 
O fortalecimento do mercado de trabalho resultou fundamentalmente na expansão do setor de serviços, o que significou a difusão de nove em cada grupo de 10 ocupações com remuneração de até 1,5 salário mínimo mensal. Juntamente com as políticas de apoio a rendas na base da pirâmide social brasileira, como elevação do valor real do salário mínimo e massificação da transferência de renda, houve o fortalecimento das classes populares assentadas no trabalho (POCHMANN, 2012, p. 10).

No entanto, tal crescimento pode não culminar na absorção dessas pessoas por um estrato social mais elevado, o da Classe Média, fazendo-as permanecer na posição de classe trabalhadora. A despeito de sua incorporação no mercado de trabalho no setor de serviços - o que lhes tem permitido acesso a empregos formais e estáveis - seu baixo nível educacional ou formação superior no sistema privado mais massificado e com menor reconhecimento no mercado de trabalho, somados à sua pouca experiência profissional, são fatores que as mantém nas classes populares, apenas empregadas e, por isso, com maior poder de consumo do que no passado.

O sociólogo Jessé de Souza (2012), em Os Batalhadores Brasileiros: nova classe-média ou nova classe trabalhadora também dedicase a apresentar em que medida este estrato da população se distingue da tradicional classe média, bem como da privilegiada classe alta. Em sua visão: "Acreditamos estar diante de um fenômeno social e político novo e muito pouco compreendido [...] o da constituição não de uma nova classe média, mas sim de uma nova classe trabalhadora no nosso país, nas últimas décadas." (SOUZA, 2012, p. 47). Ainda de acordo com o autor:

As classes dominantes - classe média e alta - se definem, antes de tudo, pelo acesso aos dois capitais impessoais que asseguram, por sua vez, todo tipo de acesso privilegiado a literalmente todos os bens (materiais ou ideais) ou recursos 
escassos em uma sociedade de tipo capitalista moderna (SOUZA, 2012, p. 48).

Segundo Marilena Chauí, em texto publicado no livro em que avalia os governos Lula e Dilma, a classe social não é um dado fixo, é um fazer histórico. A partir dessa constatação, "se é nisso que reside a possibilidade transformadora da classe trabalhadora, é nisso também que reside o risco de absorção ideológica, sendo o primeiro sinal deste risco justamente a difusão de que há uma nova classe média no Brasil" (CHAUÍ, 2013, p. 131). Em sua perspectiva, existiria uma propagação por toda a sociedade do ideário liberal da competência e da racionalidade de mercado como promessa de sucesso, discursos estes que, de acordo com a filósofa, acabam por ser aderidos pelas próprias camadas populares, chamadas por ela também de "novos trabalhadores".

Uma perspectiva mais afeita às diferenças com relação à suposta emergência de uma "nova classe-média" é encontrada na análise de Celi Scalon e André Salata (2012). Os sociólogos mostram que mesmo sob critérios puramente estatísticos, como os aventados pelo criador do termo "nova classe-média", a diminuição da miséria e da pobreza em anos recentes não tem criado efetiva ascensão social. A base da pirâmide de renda continua muito distante dos estratos médios tradicionais. Quando cruzam os dados econômicos com diferenças raciais e de nível educacional isto fica ainda mais patente. Os estratos médios e altos da população brasileira continuam muito mais ricos do que os baixos, o que é reforçado/mantido por seu nível educacional comparativamente mais alto e seu "fechamento" racial: "A classe média obtêm rendimentos nitidamente mais elevados (com exceção dos trabalhadores não manuais de rotina), é mais fechada - em relação à educação e raça -, e tende a possuir mais bens de consumo" (SCALON; SALATA, 2012, p. 402). 
Nossa pesquisa tende a corroborar as afirmações de Scalon e Salata, no que toca à centralidade do tipo de ocupação para definir a experiência de classe de nossas interlocutoras. O fato de a maioria estar empregada, inclusive formalmente, é algo positivo, mas que não pode nos impedir de perceber que ocupam ainda posições subalternas na esfera dos serviços, a que mais se expandiu com o avanço econômico dos últimos anos. O emprego e a renda aferida nesse tipo de trabalho não modifica a carência de capital cultural ou econômico das jovens para uma efetiva ascensão aos estratos médios. Suas falas demonstram que vivem uma ampliação de perspectivas em relação às suas mães, em especial em relação à esfera do consumo, mas também revelam dúvidas com relação à estabilidade financeira e a independência.

Nossas colaboradoras ocupam posições do comércio e dos serviços no terceiro setor, espremidas entre os desempregados ou ocupados em funções como a de doméstica e trabalhadores do setor produtivo e aqueles em ocupações mais qualificadas, bem pagas e socialmente reconhecidas. Suas falas expressam uma experiência de instabilidade e incerteza que remetem à origem humilde como veremos adiante.

Lúcia relatou-nos em entrevista pelo Facebook: "aqui em casa a gente se vira como pode [...] eu não ajudo meus pais, pois tenho que pagar o FIES". A jovem tem 26 anos, mora em Palmas, trabalha em uma concessionária de veículos. O pai e a mãe vendem caldo de cana na rua e todos os irmãos trabalham: "lá em casa meus pais pagam as contas da casa, mas roupas, remédios, cursos, estudos, nós mesmos pagamos". Lúcia relatou de forma detalhada a educação rigorosa e religiosa que recebeu dos pais evangélicos. Lúcia disse ter aprendido tudo o que sabe sobre roupas, cuidados relacionados à feminilidade, relacionamentos amorosos e sexo, por meio de duas fontes, primeiro as revistas femininas e depois a internet: "tudo o que sei aprendi nesses lugares, hoje em dia, jogo tudo no mestre google" (risos). 
Leila é outra colaboradora que enfrentou dificuldades para cursar a faculdade: "eu tranquei a faculdade para tomar um fôlego financeiro, e me organizar". Ela mora em Belo Horizonte, com a mãe dona de casa e o padrasto caminhoneiro. Tem 29 anos e trabalha como assistente administrativa em um escritório de advocacia empresarial, mas começou sua vida profissional aos 19 anos com vistas a ajudar em casa, pagar o curso superior e adquirir independência em relação ao padrasto. Leila não tem muito contato com o pai que largou a família, com a mãe grávida, para viver com outra mulher. Encontrou o Bolsa via anúncio no MSN. Contou-nos que dentre os motivos que a fizeram ficar no site, o principal deles foi aconselhar e buscar conselhos.

Helena tem 29 anos, mora no Acre, é casada e trabalha ajudando o marido em sua loja de material de construção. Saiu de uma cidade no interior, onde morava no sítio dos pais, para tentar a vida em uma cidade maior que permitisse mais acesso aos estudos - "hoje faço pós graduação. Lá [na casa dos pais] eu morava no interior, no sítio, não consegui nem terminar of fundamental, terminei aqui.". Passou algum tempo morando com a tia que ofereceu melhores condições para ela estudar e se manter, no entanto, enfrentou um cotidiano de trabalho não remunerado que exercia em troca de casa e comida. Conheceu o marido, casou-se e teve, então, a possibilidade de continuar os estudos. A jovem conheceu o Bolsa em um momento de solidão, quando o marido trouxe para morar com o casal o filho pequeno, que alterou a rotina da casa. Relatou-nos que assistia TV até a madrugada e em um programa foi mencionado um site para mulheres, o qual ela procurou com objetivo de "desabafar".

Mara, por fim, é nossa colaboradora mais velha. Com 35 anos, dois filhos e moradora da Zona Oeste do Rio de Janeiro, do bairro Paciência, dedicou-se em vários momentos a falar dos sonhos interrompidos de realizar um curso superior, por conta da maternidade prematura: "eu sempre quis fazer faculdade, mas não consegui. Me casei 
muito cedo e depois vieram as crianças. Quem sabe agora, depois de terminar a reforma da casa". Há muitos anos Mara trabalha como instrumentalista em um consultório dentário. No momento da pesquisa, ela morava com a mãe, que após um acidente, havia desenvolvido falta de memória e problemas motores. A irmã também trabalha para ajudar no orçamento, mas segundo Mara, é ela quem arca com os gastos principais.

O convívio com essas mulheres tem nos levado a reconhecer que a experiência que molda suas vidas pode ser descrita como a da subalternidade, no caso, uma subalternidade feminina das classes populares. São mulheres que dialogam pela rede compartilhando desejos e aspirações, mas principalmente temores e incertezas. Entre os desejos despontam os de encontrar um companheiro, casar-se, constituir família assim como os de ter acesso a bens de consumo, de poder sair da casa dos pais e "ter a própria vida". Dentre receios e medos sempre figuram os relativos à instabilidade econômica, à permanência no emprego, às dificuldades com o orçamento pessoal e familiar e, principalmente, aos problemas enfrentados na relação afetiva, vista como aquilo que, para ter sucesso, deve ser mantida, culminando no matrimônio e garantindo, mesmo que paradoxalmente, a independência feminina.

Desejos e aspirações, assim como temores e incertezas, se constituem sob a perspectiva de mulheres que são demandadas a contribuir no orçamento familiar, sem perder a função tradicional do cuidado e da assistência doméstica. Demandas facilmente conflitantes e geradoras de tensão, as quais não podem ser dimensionadas sem levar em consideração gênero, raça $\%$ cor, geração, aspectos de crença religiosa, etc.

Para fins deste artigo, embora o conceito de raça não seja foco do debate, ele surge para ilustrar o público que compõe esta pesquisa. Não se trata de termo mobilizado pelas interlocutoras de pesquisa, mas pelos pesquisadores, na medida em que nos ajuda a entender as dinâmicas de cuidado com o corpo e de alisamento dos cabelos, prática recorrente na 
Em consonância com as análises mais críticas sobre ascensão social da população de baixa renda, buscamos associar à compreensão de classe a maneira como os sujeitos se percebem na estrutura social e vivenciam sua classe a partir da experiência. Dessa forma, temos como foco questões como status ocupacional, quantidade de membros da família, presença ou não de problemas financeiros, nível educacional, local de moradia e estudos, acesso à internet, expectativas em relação ao futuro. $\mathrm{O}$ conceito de classe via experiência, como algo dinâmico, histórico e não restrito à estratificação por renda tem, aqui, parte de suas inspirações na obra de E. P. Thompson, para quem as determinações objetivas se impõem sobre seres históricos, ativos e conscientes:

Por classe, entendo um fenômeno histórico, que unifica uma série de acontecimentos díspares e aparentemente desconectados, tanto na matéria-prima da experiência como na consciência. Ressalto que é um fenômeno histórico. Não vejo a classe como uma "estrutura", nem mesmo como uma categoria, mas como algo que ocorre efetivamente (e cuja ocorrência pode ser demonstrada) nas relações humanas (THOMPSON, 1987, p. 9).

A partir disso, é possível pensar classe social como algo que se vivencia em uma relação e não como uma estrutura que se impõe aos indivíduos. A experiência de classe envolve tanto fatores objetivos e relacionais, quanto subjetivos e de experiência. Por isso nosso foco está em observar como nossas colaboradoras na pesquisa usam as mídias digitais criando redes moldadas pela mesma forma de lidar com questões econômicas, compartilhando a mesma exposição a bens de consumo e a discursos de ascensão social, mas - principalmente - a

apresentação de fotos de perfil na rede social e mesmo em dinâmicas offline, que atravessam a vida social e os espaços de lazer de nossas interlocutoras. Compreendemos raça como um processo contextual, nos termos de Avtar Brah: "Processos de racialização são, é claro, historicamente específicos, e diferentes grupos foram racializados de maneira diferente em circunstâncias variadas, e na base de diferentes significantes de 'diferença'"' (BRAH, 2006, p. 344). 
subalternidade de sujeitos formados em um nexo de diferenças, pois são mulheres das classes populares.

Joan W. Scott afirma que não são sujeitos que têm experiências, mas que as experiências formam os sujeitos. Assim, nosso intuito de visibilizar a subalternidade que molda as vidas das jovens brasileiras vai na direção "de se tornar uma forma de explorar como a diferença é estabelecida, como ela opera e como e de que maneira constitui sujeitos" (SCOTT, 1998, p. 301).

Quando falamos da experiência de subalternidade das interlocutoras de pesquisa partimos mais das concepções deexperiência que permitem pensar classe não como aquilo que unifica os indivíduos em uma identidade comum, a identidade de classe, mas como mais um dos aspectos que marcam a diferença, assim como o gênero, a raça e a sexualidade, de forma interseccional, como composição dos processos de subjetivação. A seguir exploramos essa intersecção, com maior foco no que toca às questões de classe e gênero, a partir do campo de pesquisa com o intuito de uma análise preliminar, mas que contribua para compreender aspectos pouco explorados do fenômeno do recente aumento do emprego e da renda nas classes trabalhadoras brasileiras.

\section{“EU QUERO TER MINHAS COISINHAS"}

Nesta parte do texto retomaremos de forma mais sistemática o campo empírico da pesquisa. Nosso intuito será de abordar como a experiência da conexão por meio das mídias digitais é representante de uma tensão fundante entre a ampliação dos horizontes aspiracionais e as ainda escassas ferramentas que permitiriam, por outro lado, trilhar caminhos seguros de ascensão.

A sociabilidade em rede das mulheres das classes populares possibilita um debate que extrapola os limites da renda como marcador 
fundamental deste grupo social. Ao contrário do que apontam os discursos hegemônicos sobre o assunto, ela evidencia formas criativas e dinâmicas de lidar com uma suposta melhoria das condições de existência enquanto sujeitos da dita "Classe $\mathrm{C}$ " e com as características da origem subalterna.

Mostraremos que nãose trata de uma simples adesãoideológica às dinâmicas de mercado, possibilitadas com a melhoria dos padrões de vida. E, mesmo as esferas que parecem soar como portadoras de um conservadorismo, como a relação afetiva e o casamento, tema chave nesta dinâmica online, são ressignificadas pelas colaboradoras e negociadas no âmbito da relação, também como meio de se emancipar da origem socioeconômica baixa.

Notamos que a relação amorosa adquire um caráter preponderante no universo apresentado e nas práticas de ajudamútua feminina online, bem como dá o tom da sociabilidade em rede no Bolsa de Mulher, como aquilo que pode impulsionar os sujeitos para além da reprodução de sua origem subalterna. Por um lado, os desejos em torno do casamento e da consolidação de laços afetivos fortes demanda dessas mulheres uma série de características emocionais, tais como: que sejam delicadas e sensuais, que não estejam sempre disponíveis para os homens, que tenham habilidades sexuais que escapam da monotonia da relação, que sejam independentes sem exercer dominância, etc. Por outro lado, temos o namoro e o casamento como esfera que possibilita a saída do campo da família de origem e da construção da própria vida.

A dinâmica online aponta para uma constituição de redes de amizade e, mais do que isso, para a possibilidade diária de falar sobre as questões afetivas, sobre as faltas e ausências que fazem da internet um espaço de contato com experiências que podem ser compartilhadas em tempo real. Nossas colaboradoras principais, vinculadas a um cotidiano de trabalho durante o dia e de estudos à 
noite, impossibilitadas de circular entre diferentes meios devido à falta de veículo próprio e de renda, têm a internet como um lugar privilegiado onde é possível fazer, dentre outras coisas, amigas. Isso fica evidente no tempo gasto tanto com a plataforma do Bolsa, quanto com os grupos no Facebook e Whatsapp que pode chegar a conversas que se estendem ao longo do dia, sobre detalhes do cotidiano.

Nestes espaços, as jovens falam de todos aqueles detalhes que, também por não quererem expor em meio ao contexto do local onde moram, preferem manter na rede, onde estão mais protegidas dos olhares conhecidos, curiosos e, muitas vezes, julgadores da vizinhança. Como nos relatou Leila: "eu prefiro as amigas do Bolsa, falo muito mais do que acontece comigo a elas, eu gosto de opinar e de ouvir". $\mathrm{O}$ que permite aventar a hipótese de que a novidade nesse espaço relacional é a possibilidade de compartilhar experiências que antes ficariam "caladas" ou seriam filtradas moralmente.

A rede online emergiu enquanto uma espécie de espaço relacional destensionador, no qual também pode ser possível encontrar conforto para as pressões vividas no trabalho e na vida familiar. Diferente dos contextos off-line, em nossos perfis pessoais, podemos deletar ou bloquear pessoas com as quais não queremos mais contato, que nos causam mal-estares e proporcionam conflitos. "Assim, as relações mediadas constituiriam em si mesmas uma zona de conforto nova, com critérios próprios e muito distintos dos que regiam as experiências em grupo ou comunitárias não-mediadas" (MISKOLCI, 2012, p. 36).

No caso das colaboradoras da pesquisa, os assuntos expostos sobre a esfera afetiva evidenciam a maior agência trazida pelas mídias digitais, de permitir tratar tanto das questões do cotidiano da casa ou amoroso, quanto abordar temas delicados como traição, desejos sexuais não compartilhados com marido e namorado, violência doméstica, defeitos dos parceiros, anseios de abandono da vida e da 
rotina atuais, vontades de promover transformações, questões sobre as práticas sexuais fora e dentro do casamento.

$\mathrm{O}$ que este espaço relacional das redes de sociabilidade online traz de novo é a possibilidade de expor experiências e vivências de forma rápida e ativa em meio a um cotidiano repleto de demandas no tocante ao trabalho, aos estudos, à vida em família, às dificuldades financeiras e às relações amorosas. É comum tanto nos grupos do Facebook, quanto naqueles criados via aplicativo de celular longas conversas em torno de questões que exigem não somente auxílio imediato, mas um espaço de desabafo e conforto. Mara relatou no grupo do Whatsapp, após falar dos problemas com a instabilidade financeira do atual emprego: "às vezes me impressiona como vocês, apesar da distância, estão muito mais próximas de mim".

A busca pela rede online também aparece de maneira relacional à forma com que conduzem a relação afetiva e a esfera pessoal, objetivando ter independência, em meio às dificuldades enfrentadas no cotidiano, como, por exemplo, o contexto de migração em busca de melhores condições de vida, as inseguranças profissionais e as instabilidades econômicas, e, por fim, as demandas afetivas e emocionais de buscar e manter uma relação amorosa. "Eu sempre quis casar, ter meu espaço, minhas coisinhas", apontou-nos Lúcia no momento em que falávamos sobre os preparativos para seu casamento e sobre os anseios do futuro pautados por constituir família. O casamento como esfera de oportunidade para realizar sonhos, estudar, construir-se enquanto sujeito que teve sucesso ao deixar a casa dos pais e o destino sem promessas do contexto natal de infância e de adolescência aparece também nas falas das outras representantes do universo da pesquisa ${ }^{10}$.

A experiência de Helena está marcada por esse movimento de busca por melhores condições de vida e envolve fluxos migratórios,

10 Miriam Adelman (2011) apresenta e analisa ampla bibliografia sobre as relações entre amor e dinheiro em seu artigo "Por amor ou por dinheiro? Emoções, discursos, mercados". 
tentativas de se consolidar em um ambiente mais propício ao processo de ascensão tanto por meio da educação ou do trabalho, quanto tendo a relação afetiva como importante no auxílio para dividir as contas e conseguir manter-se. A jovem relatou detalhes sobre a relação de exploração mantida pela tia até conhecer o atual companheiro, com quem foi morar. Por meio da união, conseguiu direcionar de outra forma sua vida incluindo os estudos.

Não foi fácil, não. Às vezes os parentes não são o que imaginamos. Ela [a tia] era muito difícil, além de não compreender minha vontade de estudar. Eu morava com ela e trabalhava, tanto na casa dela, quanto na loja. Eu não sei se você já viveu no sítio e sabe como é, mas sempre tem um parente bacana que quer te levar pra viver melhor. Eu fiquei com ela dois anos, aí eu conheci meu marido. Namoramos, casamos e tudo mudou. Agora eu posso me dedicar aos estudos.

Lucila também reforça a ideia do casamento como um meio através do qual é possível adquirir independência e segurança, ao contrário do que ressaltam os discursos sobre a manutenção dos papéis femininos na família. Quando a questionamos sobre os anseios do futuro, sobre porque gostaria de casar-se e ter família, para além das questões pautadas por um sentimento romântico, a jovem apontou aquilo que mais a agradava na ideia de se unir a alguém afetivamente, "ter a própria vida". Já o trabalho e a formação educacional são expostos ambos também como representantes de independência e de ascensão:

Sei cozinhar muito bem, coleciono receitas desde os 13 anos, sei costurar, bordar. Enfim, sei fazer bastante coisa que se liga a uma família [...] o que mais agrada na ideia de casar é ter minha casa, minhas coisas, minha privacidade, um canto pra poder chamar de meu e, claro, também dividir com a pessoa que eu amo. Mas lógico não faço só isso, sou formada em direito e trabalho em uma concessionária. Não pretendo deixar meu emprego. 
O casamento, em grande parte das falas, e, anterior a ele, o namoro, surgem ambos como um meio para tocar a própria vida em um contexto onde dividir as contas, mesmo entre duas pessoas que recebem um salário baixo, é mais vantajoso do que viver só.

O estabelecimento da relação amorosa se associa a um projeto de individualização e independência pessoal feminina em relação à família e aos pais, e o discurso em torno do namoro está, frequentemente, atravessado por esta perspectiva, como apontou Mara em uma situação de campo vivenciada em um restaurante perto de sua casa em Paciência, Zona Oeste do Rio de Janeiro - "o ex namorado só enrolou ela [sua amiga], ele não quis casar, nem nada, compraram tudo pra casa, mas tiveram que vender e ela ficou morando com os pais".

A amiga de Mara é uma jovem negra, de 27 anos que havia colocado fim ao noivado após cinco anos de relação. Nos termos de Mara, a relação amorosa nunca aparece como aquilo que deve ser aproveitado e compartilhado no momento, ela surge como algo que deve culminar no objetivo futuro, o casamento e a conquista do espaço próprio, dividido com o parceiro.

Existe uma marca geracional percebida na dinâmica das relações vivenciadas no site. As mais jovens partilham um conflito específico: busca pela autonomia vivenciando um relacionamento amoroso. Entre elas, a relação tem que culminar nesse objetivo, caso contrário pode - e talvez deva - terminar. Dentre as mulheres mais velhas, em sua maioria casadas, é comum a busca pela rede como meio de reclamação em relação ao comportamento dos maridos, até mesmo no que toca às situações de violência física ou verbal - ou mesmo um longo histórico de traições - às quais estão submetidas. Certa vez uma de nossas colaboradoras, na faixa dos 50 anos, fez uma postagem no grupo do Facebook sobre o embate físico com o marido e os discursos de amparo apontavam, com poucas exceções, para o estímulo à reconciliação. 
As mulheres mais jovens, na faixa dos 20 e 30 anos se situam em um contexto de maior acesso às informações, principalmente via mídia social, que permite reconhecerem atitudes machistas ${ }^{11}$ e contraporem-se à violência, mas que apresentam, por outro lado, um projeto de independência ainda vinculado ao parceiro, não como arrimo de família, mas como pessoa que pode contribuir com o orçamento doméstico, arcar com parte das contas e com as demandas emocionais de formação de família.

É comum a reclamação, por parte das mais jovens, sobre a escassez de homens dispostos a cultivar um relacionamento afetivo pautado por compromisso, por desejos de compartilhamento de futuro e por fidelidade. São recorrentes falas como, "está difícil encontrar um namorado", "não está fácil pra ninguém", "os rapazes não querem nada sério".

As falas acima, sobre o descontentamento com os possíveis parceiros, podem apontar para um aumento de expectativas em relação a eles, por parte de uma geração de mulheres que tem acessado de forma mais efetiva os estudos e posições profissionais, diferentes de suas mães. Esta geração de mulheres mais jovens, que compõe parte significativa das usuárias do Bolsa, viram possibilitados tanto um maior processo de individualização, de consumo de bens materiais, quanto uma maior seletividade na escolha da relação afetiva. A rede online, nesse sentido, aparece como espaço promotor de diálogos em torno da relação afetiva que merece ou não ser buscada/mantida. $\mathrm{O}$ compartilhamento de questões amorosas via internet e o contato com experiências diversas intensifica o processo reflexivo em torno dos horizontes aspiracionais dessas mulheres.

11 Diversas situações em campo nos permitiram perceber como as mulheres lidam com dinâmicas de gênero que reforçam a desigualdade. Elas mesmas mobilizam o termo "machista" ou "machismo" para falar de condutas agressivas e violentas dos próprios parceiros ou de namorados e maridos de amigas. Também há situações em que estas palavras não são mobilizadas, mas apontam para uma percepção acentuada de dinâmicas pautadas por desigualdades de gênero como, por exemplo, a divisão de tarefas na esfera doméstica que sobrecarrega as mulheres e que geram discussões entre o casal. 


\section{CONSIDERações Finais}

As mulheres com as quais dialogamos, embora façam parte de um novo momento social e econômico do país, distanciam-se de um simples desejo de galgar outras posições de classe e também apresentam uma dinâmica subjetiva multifacetada frente ao contexto tradicional de gênero no qual foram socializadas e que centra na família e no casamento a plena realização feminina. Elas querem casar, mas não só isso. Elas querem escapar da possibilidade de ter que reproduzir a origem subalterna de classe baixa dos pais e dos demais membros familiares, impedidos de ter acesso à educação e à ascensão social; querem consumir, e, sobretudo, querem ter a própria casa como espaço onde são elas que decidem a dinâmica familiar e definem sua atuação, bem como o espaço do parceiro que pode, muitas vezes, aparecer como coadjuvante.

Trata-se, portanto, de uma dinâmica específica e não homogênea, ou seja, os sujeitos aqui abordados apontaram uma discordância com os discursos que os colocam como responsáveis por uma suposta absorção do ideário individualista da racionalidade de mercado. As mulheres dessa pesquisa, além de não apresentarem essa agência pautada por um individualismo competitivo - uma vez que a própria dinâmica de formação de grupos de apoio apresenta uma proposta coletiva de lidar com as inseguranças - têm problematizado os próprios enunciados que as alocam nesses novos estratos. Carla, jovem de 29 anos, carioca, mas que atualmente mora em Campinas com o marido, relatou-nos em conversa no Whatsapp:

Com tantas classes novas eu me considero pobre. Eu moro de favor, mas fiz faculdade porque eu paguei, etc. Isso faz de mim classe media ou baixa?... Pois eu me vejo assim: moro de favor e trampo, tenho carro popular que tá pago, mas foi financiado, não me vejo nem financiando um imóvel. 
Esta fala surgiu via Whatsapp no início do ano de 2014 em uma conversa cujo tema era a violência da polícia nos bairros pobres do país e o ponto de partida para a reflexão de Carla foi a colocação de outra pessoa membro do grupo: "o que interessa para o governo é manter a classe média bem". Carla ficou incomodada com o termo "classe média", afirmou não se sentir parte daquilo que é dito tanto sobre a classe média quanto sobre as supostas classes em ascensão.

Carla tem uma história também compartilhada com outras usuárias. De família humilde viu no casamento a possibilidade de ter a própria vida e, de acordo com seus termos, "se libertar" da família conservadora ${ }^{12}$. A jovem, apesar de conviver com o enunciado mencionado constantemente pela mãe, "minha filha só sai de casa casada", via nele algo de muito conservador e ressignificou a atual convivência com o marido como uma possibilidade de não viver as regras da família de origem. Este diálogo em torno da percepção de sua posição na estrutura social como mais delicada e instável do que mostra os discursos sobre a dita Classe C, aponta como os enunciados que abarcam estes sujeitos de forma homogênea como incorporadores de uma dinâmica ideológica podem ser problematizados por quem vivencia estas dinâmicas.

Para as mulheres dessa pesquisa, é importante, antes de qualquer coisa, manter-se estável em meio a um contexto inseguro de classe e estabelecer a consolidação do relacionamento amoroso em uma época que ainda demanda delas o casamento, mas que sua geração ressignifica e negocia como possibilidade de ter o próprio espaço, com as próprias regras, distante do núcleo de origem.

12 Na fala de Carla, assim como nos discursos de outras interlocutoras e para fins deste trabalho, os termos "conservador", "conservadorismo" aparecem de modo a evidenciar dinâmicas de gênero pautadas por um processo de desigualdade. Para Carla, por exemplo, sua família é conservadora na medida em que a mãe assumiu o papel de incentivar a filha a ter um casamento de sucesso como aspecto que deveria ser central em sua vida. Para Carla, "se libertar" dessa dinâmica é ter uma carreira profissional e poder equacionar as desigualdades na esfera do lar com a maior participação do marido nos trabalhos domésticos. 
Além disso, vale ressaltar também que às mulheres cabe o suporte emocional às próprias questões pessoais, bem como às do parceiro e, no caso das casadas, da família toda, em um contexto de desejos, de consumo, mas também de incertezas e instabilidades. Este "trabalho emocional" ${ }^{13}$ demanda a mobilização de uma série de habilidades, sobretudo psicológicas e motivacionais, que podem caracterizar momentos de sobrecarga física e mental específica, o que explica, em partes, a recorrência massiva em site de ajuda na internet como o Bolsa de Mulher, onde é possível estabelecer redes de troca de experiências ${ }^{14}$.

A novidade trazida com as mídias digitais acessadas por essas mulheres é a possibilidade de equacionar as tensões entre os novos horizontes disponíveis, por um lado, e a origem e experiência subalternas por outro, em uma rede online de diversas mulheres conectadas entre si e que compartilham desses mesmos dilemas. A internet possibilita para a grande maioria desses sujeitos, um acesso a uma série de informações que, sem a rede, não seriam expostas, como mostra Lucila ao retraçar seus aprendizados com o acesso, em meio a um contexto familiar religioso e tradicional:

Eu sempre me senti muito presa e deslocada, minha mãe criou a gente de maneira restrita. E como sempre fomos crentes, queria descobrir coisas novas, aprender a conversar sobre coisas que eu não conhecia como usar batom, pintar as unhas, usar shorts, comer em uma pizzaria, sair e conhecer pessoas, namorar. Isso tudo eu só conhecia das revistas que eu lia na biblioteca e depois com a internet ficou muito mais fácil.

\footnotetext{
13 O termo "trabalho emocional" é desenvolvido por Arlie Hochschild (1983) e representa o esforço de controle das emoções na atuação em determinadas tarefas, sejam elas realizadas no espaço do trabalho ou no âmbito pessoal. Mobilizamos este termo com o intuito de abordar o esforço de controle das emoções demandado das mulheres no que toca às questões da esfera efetiva e da família.

14 Ver Facioli (2013).
} 
O fato de estarem conectadas também faz da rede um espaço de sociabilidade que auxilia nesta dinâmica complexa situada entre os anseios de independência e uma experiência marcada por rígidas posições de classe e gênero.

As relações mediadas provêm a elas a segurança de discutir sua intimidade, o que lhes auxilia a pensar sobre seus relacionamentos e adquirir um relativo sentimento de agência em uma esfera historicamente controlada para as mulheres: a da paquera, a busca ativa por parceiros amorosos, das escolhas afetivas ${ }^{15}$.

Por fim, as redes formadas por mulheres das camadas populares, com o uso de mídias digitais, têm criado processos de ajuda-mútua que permitem certo suporte em tempos de inseguranças e incertezas, mas também apontam para algo mais, especialmente no grupo das jovens focado neste artigo: elas têm sua sociabilidade ampliada, modificada e intensificada. Conectadas, elas adquirem confiança para agir e seguir projetos que buscam articular desejos de ascensão social com os de sucesso amoroso.

\section{REFERÊNCIAS}

ADELMAN, Miriam. "Por amor ou por dinheiro? Emoções, discursos, mercados". Contemporânea: Revista de Sociologia da UFSCar, São Carlos, n. 2, p. 117-138, 2011.

BELELI, Iara. Amores online. In: PELUCIO, Larissa et al. (Org.). Gênero, sexualidade e mídia: olhares plurais para o cotidiano. Marília: Cultura Acadêmica Editora, 2012.

BRAH, Avtar. Diferença, diversidade e diferenciação. Cadernos Pagu, Campinas, n. 26, p. 329-376, jan./jun. 2006.

CHAUI, Marilena. Uma nova classe trabalhadora. In: SADER, Emir (Org.). Dez anos de governos pós neo-liberais no Brasil: Lula e Dilma. São Paulo: Boitempo, 2013..

15 Sobre a busca de parceiros amorosos por mulheres brasileiras de classe-média com o uso de mídias digitais consulte Beleli (2012). 
FACIOLI, Lara. Conectadas: uma análise de práticas de ajuda mútua feminina na era das mídias digitais. 2013. Dissertação (Mestrado em Sociologia) - Universidade Federal de São Carlos, São Carlos, 2013.

McQUIRE, Scott. The media city: media, architecture and urban space. London: Sage, 2008.

MISKOLCI, Richard. A teoria Queer e a sociologia: o desafio de uma analítica da normalização. Sociologias, Porto Alegre, n. 21, p. 150-182, 2009.

MISKOLCI, Richard. A gramática do armário: notas sobre segredos e mentiras em relações homoeróticas masculinas mediadas digitalmente. In: PELÚCIO, Larissa et al. (Org.). Olhares plurais para o cotidiano: gênero, sexualidade e mídia. Marília: Cultura Acadêmica, 2012.

NERI, Marcelo. A nova classe média: o lado brilhante da base da pirâmide. São Paulo: Saraiva, 2011.

POCHMANN, Marcio. Nova classe média? O trabalho na base da pirâmide social brasileira. São Paulo: Boitempo, 2012.

SCALON, Celi; SALATA, André. Uma nova classe média no Brasil da última década? O debate a partir da perspectiva sociológica. Revista Sociedade e Estado, Brasília, v. 27, n. 2, p. 387-407, maio/ago. 2012.

SCOTT, Joan. A invisibilidade da experiência. Projeto História, São Paulo, n. 16, p. 303-304, 1998.

SOUZA, Jesse. Os batalhadores brasileiros: nova classe média ou nova classe trabalhadora. Belo Horizonte: UFMG, 2012.

SPIVAK, Gayatri. Pode o subalterno falar? Belo Horizonte: UFMG, 2010.

THOMPSON, Edward. A formação da classe operária Inglesa. Rio de Janeiro: Paz e Terra, 1987. 